\title{
Surgical Antimicrobial Prophylaxis-Where Do We Stand?
}

\author{
${ }^{1}$ Department of Pharmacology, Sri Aurobindo Medical College and \\ P.G. Institute, Indore, Madhya Pradesh, India \\ 2Department of Pharmacology, Pt. Jawahar Lal Nehru Memorial \\ Medical College, Raipur, Chhattisgarh, India \\ ${ }^{3}$ Department of Pharmacology, Ayush and Health Sciences, \\ University of Chhattisgarh, Raipur, Chhattisgarh, India \\ ${ }^{4}$ Department of Petroleum Engineering, Texas A\&M University, \\ Texas, United States
}

Anuja Jha' Manju Agrawal ${ }^{2}$ Rajesh Hishikar ${ }^{3} \quad$ Himanshu Shekhar Jha ${ }^{4}$

\begin{abstract}
Address for correspondence Manju Agrawal, MD, Department of Pharmacology, Pt. Jawahar Lal Nehru Memorial Medical College, Jail Road, Raipur 492001, Chhattisgarh, India (e-mail: manjuaagrawal@yahoo.com).
\end{abstract}

Ann Natl Acad Med Sci (India) 2021;57:102-106.

\author{
Abstract \\ Keywords \\ - surgical site infections \\ - surgical antimicrobial \\ prophylaxis \\ - National Centre for \\ Disease Control \\ - India
}

Introduction Surgical site infection (SSI) is the commonest preventable health care-associated infection among postoperative cases. Several guidelines are available for surgical antimicrobial prophylaxis (SAP) and other measures which prevent SSI. National Center for Disease Control (NCDC), India, has also provided a guideline for prevention of SSI in 2016. In this study we have compared the NCDC, India, guideline with WHO (World health organization) and American Society of Health System Pharmacists (ASHP) guidelines. The timing of antimicrobial agent administration is the only parameter which is included in all the three guidelines. As per NCDC and ASHP it should be within 60 minutes of incision while as per WHO it is within 120 minutes of incision.

Materials and Methods This was a prospective observational study-104 patients undergoing surgery in general surgical ward between January 2016 and June 2017 were included in this study. The NCDC guideline was compared with WHO and ASHP guidelines. Real data comparison was done for those parameters which were included in all the three guidelines.

Statistical Analysis Datawere analyzed using descriptive methods and chi-square test. Results None of the patients in our study received SAP within 60 minutes of incision. In $70 \%$ cases it was administered within 2 hours of incision and in the remaining $30 \%$ it was administered after more than 2 hours. There was no significant difference in the incidence of SSI among these two groups.

Conclusion NCDC SAP guideline helps in rational use of antimicrobials. Increasing the duration for SAP may be added in the NCDC guidelines. Inclusion of certain additional parameters like weight-based doses and consideration for other comorbidities will help in patient- and procedure-specific SAP. Antimicrobial stewardship should be encouraged in all the hospitals and should follow local antimicrobial resistance pattern. This will assist in therapy decision, policy making, and evidence-based treatment. published online May 11, 2021
DOI https://doi.org/

$10.1055 / \mathrm{s}-0041-1728972$ ISSN 0379-038X (c) 2021. National Academy of Medical Sciences (India).

This is an open access article published by Thieme under the terms of the Creative Commons Attribution-NonDerivative-NonCommercial-License, permitting copying and reproduction so long as the original work is given appropriate credit. Contents may not be used for commercial purposes, or adapted, remixed, transformed or built upon. (https://creativecommons.org/licenses/by-nc-nd/4.0/).

Thieme Medical and Scientific Publishers Pvt. Ltd. A-12, 2nd Floor, Sector 2, Noida-201301 UP, India 


\section{Introduction}

Surgical site infections (SSIs) are infections of the incision, organ, or space that occur after surgery. ${ }^{1}$ It is one of the most common hospital-acquired infections (HAI) which are defined as infections acquired during hospital care, which were either not present or incubating at the time of admission. ${ }^{2,3}$ SSIs can adversely affect both the patients and the health care system. These adversities can be in terms of prolonged hospital stay, excessive cost, long-term disability, and may even result in fatal outcome. Antimicrobial resistance and increased financial cost to the health care system are additional burden. Patients who develop SSIs are up to 60\% more likely to spend time in an intensive care unit, five times more likely to be readmitted to the hospital, and two times more likely to die as compared with the patients without SSI. ${ }^{4}$ Surgical antimicrobial prophylaxis (SAP) is one of the preoperative actions for prevention of SSI. ${ }^{5,6}$ There are various guidelines for SAP-Centers for Disease Control and Prevention (CDC) guidelines, American Society of Health System Pharmacists (ASHP) therapeutic guidelines on antimicrobial prophylaxis in surgery, Scottish Intercollegiate Guideline Network (SIGN) guidelines, and National Institute for Health and Care Excellence (NICE) guidelines. ${ }^{7-10}$ In India, National Centre of Disease Control (NCDC) 2016 has provided guidelines for SAP. ${ }^{11} \mathrm{WHO}$ has also identified inconsistencies in recommendations of national guidelines and published its guideline in 2016. ${ }^{12,13}$ Comparison of different guidelines showed antimicrobial prophylaxis is the only parameter common to all. Variation in the timing of drug administration was seen among different guidelines. Hence, the present study was taken up to redefine our guideline.

\section{Materials and Methods}

\section{Study Area}

The present study was conducted between January 2016 and June 2017 at the department of surgery and pharmacology, Pt. Jawahar Lal Nehru Memorial Medical College and Dr. Bhimrao Ambedkar Memorial Hospital, Raipur, Chhattisgarh. This is a tertiary care hospital with $\sim 1,130$ beds. The study was conducted after approval from the scientific and ethics committee.

\section{Study Design}

This was a prospective observational study with a two-step comparison to achieve the objective of comparison of SAP guidelines provided by NCDC, India, with the guidelines of ASHP and WHO. The first step involved comparison of these guidelines for the analysis of following parameters:

- Choice of antimicrobial agent.

- Optimal timing for SAP administration.

- Number of doses (initial dosing and intraoperative dosing).

- Duration of antimicrobial therapy.

- Recommendations for special patient population.

- Other preventive measures for SSI prevention.

- Evidence-based or not.
The next step was the real data comparison for only those parameters which were included in all the three guidelines.

\section{Study Population}

One hundred four patients undergoing either elective or emergency surgery in the surgery department were included in this study. The selection of patients was based upon the inclusion and exclusion criteria. All the patients older than 18 years who were willing to give informed consent were included in this study. All types of wound, that is, clean, clean-contaminated, contaminated, and dirty were included in our study. Cases were from trauma, breast, gastrointestinal, and genitourinary areas. Our exclusion criteria were patients with diabetes mellitus, immunocompromised status, prior symptomatic infection at the site distant to the proposed surgery site, antimicrobial prophylaxis for various reasons, known history of drug allergy, and smoking. Pregnant and lactating women were also excluded from this study.

\section{Observations}

- Table 1 shows the comparison of SAP guidelines. Real data analysis was done only for the timing of initial dose as this was the only parameter included in all the three guidelines, as evident from Table 1 . None of the patients in our study received the dose within 60 minutes of incision. We found that the initial dose of antimicrobial agent was administered within 2 hours of incision in $70 \%$ cases while in the remaining 30\% it was after more than 2 hours of incision. SSI incidence rate among these two groups were compared.

- Table 2 compares the SSI incidence rate. Using chisquare test (likelihood ratio) $p$-value is 0.572 , which is not significant.

\section{Statistical Analysis}

The data collected were analyzed by using descriptive statistics and chi-square test. The observations were depicted in the form of tables and graphs.

\section{Discussion}

Surgical site infection has always been a challenge for health care system. Several strategies have been developed to reduce their incidence which can be dated back to use of carbolic acid by Lister. ${ }^{14}$ Development of evidence-based guidelines have helped to reduce SSI incidence rate.

National treatment guidelines for antimicrobial agent use in infectious diseases were published by National Centre for Disease Control, government of India in 2016. A syndromic approach for empirical therapy of common infections including surgical antimicrobial prophylaxis has been provided in this guideline. ${ }^{11}$

In this study we have compared NCDC (India), ASHP, and WHO guidelines for SAP.

ASHP and WHO have provided evidence-based recommendations while NCDC guideline has not mentioned these. Evidence gives quality and strength to the recommendations. In future guidelines, evidence should be incorporated which will strengthen the dependability of the guidelines. $3,8,11$ 
Table 1 Comparison of NCDC guideline with ASHP and WHO guidelines

\begin{tabular}{|c|c|c|c|}
\hline & NCDC, India, guideline & ASHP guideline & WHO guideline \\
\hline Choice of antimicrobial agent & $\begin{array}{l}\text { Choice of prophylaxis based } \\
\text { on procedure and local } \\
\text { antibiogram }\end{array}$ & Surgical procedure specific & Not mentioned \\
\hline Timing of initial dose & $\begin{array}{l}\text { Within } 60 \text { minutes before } \\
\text { incision }\end{array}$ & $\begin{array}{l}\text { Within } 60 \text { minutes before } \\
\text { incision }\end{array}$ & $\begin{array}{l}\text { Within } 120 \text { minutes before } \\
\text { incision }\end{array}$ \\
\hline $\begin{array}{l}\text { Dosing and intraoperative } \\
\text { dosing }\end{array}$ & $\begin{array}{l}\text { Single dose, intraoperative } \\
\text { dose based on procedure } \\
\text { duration and agent used for } \\
\text { prophylaxis }\end{array}$ & $\begin{array}{l}\text { Single dose, weight-based } \\
\text { dosing } \\
\text { Intraoperative dose if dura- } \\
\text { tion of surgery exceeds two } \\
\text { half-lives of drug }\end{array}$ & Not mentioned \\
\hline Duration & $\begin{array}{l}\text { Should not be given beyond } \\
\text { surgery duration except in } \\
\text { cardiothoracic surgery }\end{array}$ & $\begin{array}{l}\text { Single dose or continuation } \\
\text { for less than } 24 \text { hours }\end{array}$ & Not mentioned \\
\hline Special patient population & Not mentioned & $\begin{array}{l}\text { For pediatric patients, } \\
\text { patients with hepatic and } \\
\text { renal dysfunction, patients } \\
\text { with prosthesis, patients with } \\
\beta \text {-lactam allergy }\end{array}$ & Not mentioned \\
\hline $\begin{array}{l}\text { Other preoperative measures } \\
\text { to reduce SSI }\end{array}$ & Has not been provided & Has been provided & Has been provided \\
\hline Evidence based & No & Yes & Yes \\
\hline
\end{tabular}

Abbreviations: ASHP, American Society of Health System Pharmacists; NCDC, National Center for Disease Control; SSI, Surgical site infection; WHO, World Health Organization.

Table 2 Distribution of incidence of SSI based on timing of SAP

\begin{tabular}{|l|l|l|}
\hline \multirow{2}{*}{$\begin{array}{l}\text { Timing of antimicrobial } \\
\text { agent administration }\end{array}$} & \multicolumn{2}{|l|}{ SSI } \\
\cline { 2 - 3 } & Yes & No \\
\hline Within 2 hours of incision & 13 & 60 \\
\hline$>2$ hours of incision & 7 & 24 \\
\hline
\end{tabular}

Abbreviations: SSI, surgical site infection; surgical antimicrobial prophylaxis.
As per ASHP and NCDC guidelines, antimicrobial agent should be administered within 60 minutes before incision while WHO has recommended it within 120 minutes before incision (considering the half-life of the drug). WHO has provided evidence that significant harm was seen if the drug was administered after 120 minutes of incision while no significant difference was found for time intervals within 60 or 120 minutes of incision. ${ }^{10-12}$

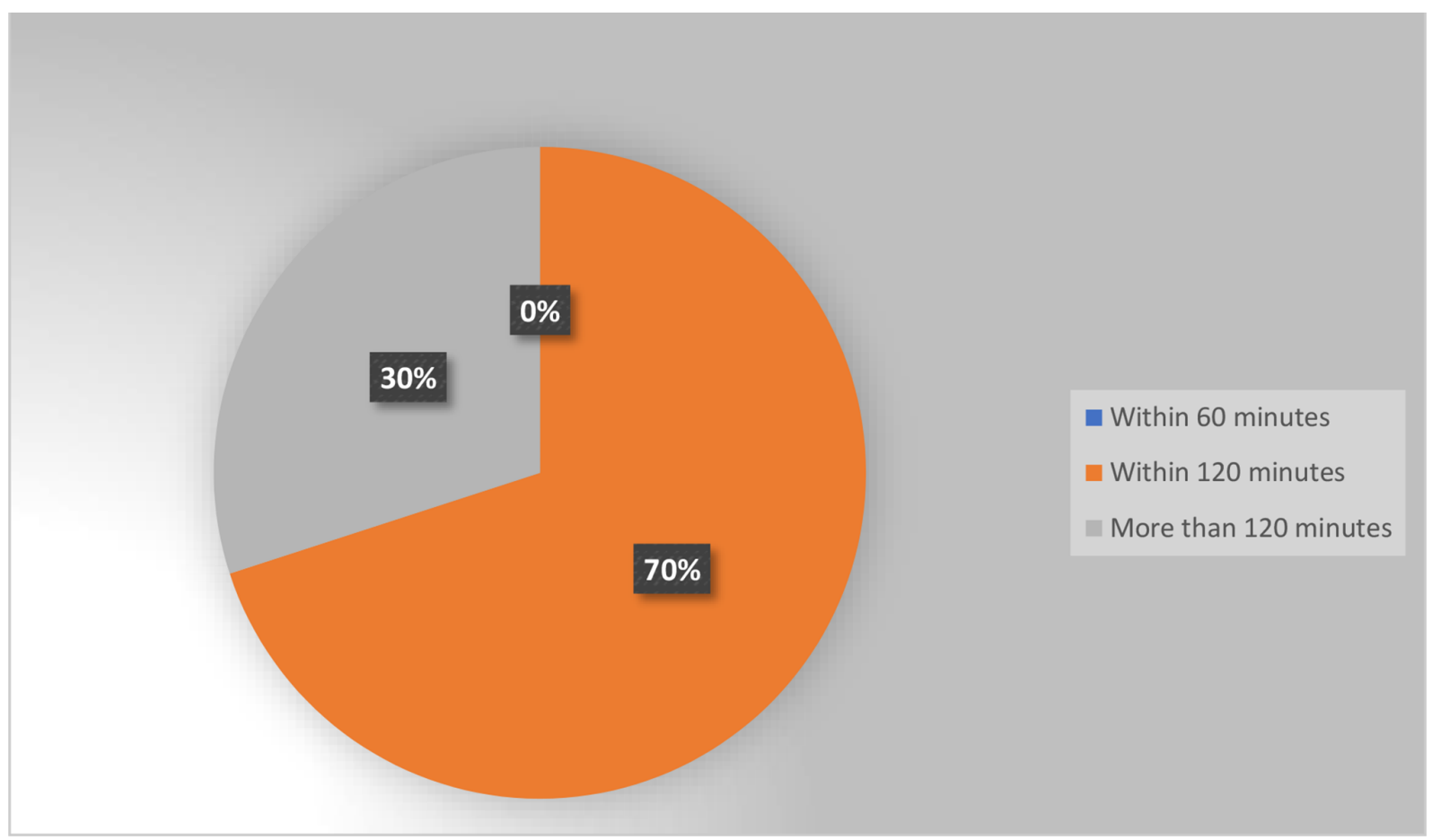

Fig. 1 Distribution of patients based on surgical antimicrobial prophylaxis (SAP) timing.

Annals of the National Academy of Medical Sciences (India) Vol. 57 No. 3/2021 @ 2021. National Academy of Medical Sciences (India). 
In this study, antimicrobial agent was administered within 120 minutes before incision in $70 \%$ cases while none of the cases received it within 60 minutes before incision. Another study has also reported nonadherence of timing for antimicrobial agent administration. ${ }^{15}$ Further, in contrast to WHO finding, no significant difference in incidence rate of SSI was found in this study between the two groups of "within 120 minutes" and "more than 120 minutes." This could be due to small sample size and type of wound (number of clean wounds were higher in the more than 120 minutes group). Based on WHO study, NCDC guidelines can also increase the drug administration time to within 120 minutes of incision as no significant increase in SSI was observed with this. This change will improve the rate of adherence with the NCDC guideline as there is shortage of health care workers in our country.

At present WHO has not provided recommendation about choice, dose, intraoperative dose, and type of surgery requiring SAP. Separate guidelines will be published by WHO in future. ${ }^{13}$ ASHP has provided evidence-based guideline for all these parameters. ${ }^{5}$

As per ASHP, dosing of antimicrobial agent should be based on body weight. This helps in dosing for obese and pediatric patients. Obesity itself is one of the risk factors for SSI as it interferes with the pharmacokinetic of the drug. They have also provided recommendation for selection of antimicrobial agent and their alternatives based on surgical procedures such as alternative in $\beta$-lactam allergic patients. ${ }^{5}$ NCDC guideline recommends fixed doses, irrespective of body weight. Also, alternatives have not been provided. ${ }^{11}$ There should be national-level surveillance to find out the resistance pattern in different parts of our country. This will work toward prescribing the most efficacious drug and will reduce failure.

Adequate serum drug concentration should be maintained throughout the whole procedure including at time of wound closure which may not be so, in case of prolonged surgeries. ${ }^{16}$ To overcome this ASHP recommends intraoperative dosing if duration of surgery exceeds more than two half-lives of the drug or if there is excessive blood loss. They have recommended dosing interval for drugs based on their half-lives. NCDC also recommends intraoperative dosing for prolonged surgery; however, the cutoff point to define the prolonged period is not mentioned, resulting in lack of uniformity among prescribers. There should be clarification on duration of prolong surgery in our guideline.

In patients with indwelling drain or intravascular catheter a single dose of surgical antimicrobial prophylaxis or continuation of SAP for less than 24 hours is recommended by ASHP. ${ }^{8}$ WHO also advocates against the prolongation of SAP after completion of the operation. ${ }^{12} \mathrm{NCDC}$ too recommends that it should not be used beyond the completion of surgical procedure (except for cardiothoracic surgery where 48 hours is permissible); however, there is no clarification for usage in patients with catheter and drain. ${ }^{11}$

ASHP has provided guidance for special patient population like patients with hepatic and renal impairment, and pediatric and obese patients. They mention that the dose need not be modified when given as a single dose in patients with hepatic and renal impairment. Weight-based dosing has been done to address pediatric and obese patients. They have also recommended use of vancomycin and mupirocin in patients colonized with MRSA. ${ }^{11}$ Studies have shown that $60 \%$ microorganism isolated from SSI wound show multidrug resistance pattern. ${ }^{11}$ These data point toward the need of addressing MRSA colonization. NCDC has not endorsed this population.

One of the most important questions is who requires SAP? Should it be given to everyone undergoing surgical procedures? NCDC has generalized its recommendations for all the patients. ${ }^{11}$ ASHP narrows it down to the procedures associated with high rate of infection (clean-contaminated and contaminated procedures) and some clean procedures which are associated with severe consequences of infection. ${ }^{8}$ Use of antimicrobial agent in dirty wound is considered as treatment rather than prophylaxis and it should be continued after the procedure. ${ }^{10}$ This will reduce indiscriminate use of antimicrobial agent.

Although SAP plays an important role in reducing the rate of SSI, there are several other factors which play role in the development of SSI. Other preoperative pharmacological recommendations by ASHP and WHO which are not specified by NCDC, are as follows $8,11,12$

- Preoperative bathing with plain or antimicrobial soap.

- Decolonization with mupirocin ointment for prevention of Staphylococcus aureus infection in nasal carriers.

- An alcohol-based antiseptic solution containing chlorhexidine gluconate should be preferred for surgical site preparation.

- Antimicrobial sealants should not be used after surgical site skin preparation.

As a holistic approach, all these factors should be addressed to complement SAP for a more effective prevention of surgical site infection. Also, antimicrobial stewardship intervention improves appropriateness of SAP. ${ }^{17,18}$

\section{Conclusion}

NCDC (India) has provided a guideline for SAP, which will promote the rational use of antimicrobial agent, leading to effective cure of infection as well as decrease in preventable SSIs. Addition of certain more parameters like weight-based dosing, consideration for catheters and drains, clarification on duration of prolonged surgery, addressing MRSA colonization, and specifying the choice of antimicrobial agent and its duration depending on the type of wound (procedure specific) with evidence will help in formulating an inclusive guideline so as to guide the surgeons in the selection of safe and effective antimicrobial agents. Further, continuous monitoring of the hospitals should be done to find out the rate of adherence to the guideline and the reason of nonadherence which will help in necessary amendments in the guideline so that it can be implemented completely and efficiently. 


\section{Conflict of Interest}

None declared.

\section{References}

1 Berríos-Torres SI, Umscheid CA, Bratzler DW, et al. Healthcare Infection Control Practices Advisory Committee. Centers for Disease Control and Prevention guideline for the prevention of surgical site infection, 2017. JAMA Surg 2017;152(8):784-791

2 World Health Organization. Prevention of hospital-acquired infections. Available at: https://www.who.int/csr/resources/ publications/whocdscsreph200212.pdf

3 Berríos-Torres SI, Umscheid CA, Bratzler DW, et al. Centers for disease control and prevention guideline for the prevention of surgical site infection. JAMA Surgery 2017;152(8):784-791

4 Bratzler DW, Houck PM. Surgical Infection Prevention Guideline Writers Workgroup. Antimicrobial prophylaxis for surgery: an advisory statement from the National Surgical Infection Prevention Project. Am J Surg 2005;189(4):395-404

5 Allegranzi B, Bischoff P, de Jonge S, et al. WHO Guidelines Development Group. New WHO recommendations on preoperative measures for surgical site infection prevention: an evidence-based global perspective. Lancet Infect Dis 2016;16(12): e276-e287

6 Mazaki T, Mado K, Masuda H, Shiono M, Tochikura N, Kaburagi M. A randomized trial of antibiotic prophylaxis for the prevention of surgical site infection after open mesh-plug hernia repair. Am J Surg 2014;207(4):476-484

7 Mangram AJ, Horan TC, Pearson ML, et al. Guideline for prevention of surgicalsite in fection, 1999. Am J Infect Control 1999;27(2):97-134

8 American Society of Health- System Pharmacists. Clinical practice guidelines for antimicrobial prophylaxis in surgery. Available at: https://www.ashp.org/-/media/assets/policyguidelines/docs/therapeutic-guidelines/therapeuticguidelines-antimicrobial-prophylaxis-surgery.ashx. Accessed April 7, 2021
9 Scottish Intercollegiate Guidelines Network. Antibiotic prophylaxis in surgery-a national clinical guideline. http:// www.sign.ac.uk/assets/sign104.pdf. Published 2014. Accessed October 15, 2017

10 National Institute for Health and Care Excellence. Surgical site infections: preventionand treatment. https://www.nice.org. uk/guidance/cg74. Published 2017. Accessed October 15, 2017

11 National Centre for Disease Control. National Treatment Guidelines for Antimicrobial Use in Infectious Diseases. http://www.ncdc.gov.in/writereaddata/mainlinkfile/File622. pdf. Published 2016. Accessed October 15, 2017

12 World Health Organization. Global guidelines for the prevention of surgical site infection. http://www.who.int/gpsc/ ssi-guidelines/en/. Published 2016. Accessed October 15, 2017

13 Allegranzi B, BagheriNejad S, Combescure C, et al. Burden of endemic health-care-associated infection in developing countries: systematic review and meta-analysis. Lancet 2011;377(9761):228-241

14 Pitt D, Aubin JM. Joseph Lister: father of modern surgery. Can J Surg 2012;55(5):E8-E9

15 Rehan HS, Kakkar AK, Goel S. Surgical antibiotic prophylaxis in a tertiary care teaching hospital in India. Int J Infect Control 2010. Available at: https://citeseerx.ist.psu.edu/viewdoc/download?doi=10.1.1.430.2608\&rep=rep1\&type=pdf. Accessed April 7, 2021

16 Kanjii S, Antimicrobial prophylaxis in surgery. In: DipiroJ T, Talbert RL, Yee GC, Matzke GR, Wells BG, Posey LM, eds. Pharmacotherapy: A Physiological Approach. 9th ed. New York, NY: McGrawHill; 2015;1991-2006

17 Tiri B, Bruzzone P, Priante G, et al. Impact of antimicrobial stewardship interventions on appropriateness of surgical antibiotic prophylaxis: how to improve. Antibiotics (Basel) 2020;9(4):168

18 Riggi G, Abbo LM. The role of antimicrobial stewardship programs to optimize antibiotics use in the surgical departments. In: Infections in Surgery. Cham:Springer;2021;247-260 